\title{
Fatigue Life Estimation of an Elastomeric Pad by $\varepsilon-N$ Curve and FEA
}

\author{
Baban Suryatal', Haribhau Phakatkar2, Kasilingam Rajkumar³, \\ Ponniah Thavamani ${ }^{3}$ \\ ${ }^{1}$ Department of Mechanical Engineering, PDEA's College Engineering, Manjari (Bk.), Pune, India \\ ${ }^{2}$ Department of Mechanical Engineering, Vishwakarma Institute of Technology, Pune, India \\ ${ }^{3}$ Indian Rubber Manufacturer's Research Association, Thane (W), India

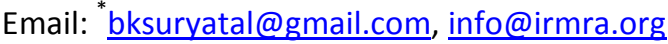

Received 2 March 2015; accepted 25 March 2015; published 27 March 2015

Copyright (C) 2015 by authors and Scientific Research Publishing Inc.

This work is licensed under the Creative Commons Attribution International License (CC BY). http://creativecommons.org/licenses/by/4.0/

(c) (7) Open Access

\section{Abstract}

Failure analysis and fatigue life prediction are very important in the design procedure to assure the safety and reliability of rubber components. The fatigue life of a railway elastomeric pad is predicted by combining the test of material properties and finite element analysis (FEA). The specially developed chloroprene rubber material's fatigue life equation is acquired based on uniaxial tensile test and fatigue life tests performed on the dumbbell specimens of the chloroprene rubber. The same chloroprene rubber was developed at Indian Rubber Manufacturer's Research Association, Thane. The strain distribution contours and the maximum total principal strains of the elastomeric pad at different compressive loads are obtained using finite element analysis method. The software used for the FEA was ANSYS. The three parameter nonlinear hyperelastic Mooney-Rivlin Model and plane 182 elements were used for finite element analysis. The critical region cracks prone to arise are obtained and analysed. Then the maximum first principal elastic strain was used as the fatigue damage parameter, which is substituted in the chloroprene rubber's fatigue life equation, to predict the fatigue life of an elastomeric pad in the number of cycles at different compressive loads. The results were compared with the technical requirements given by Indian Railway's Research Designs and Standards Organization. These requirements were achieved up to certain extents. The results were also compared with the data available in the literature and a similarity was observed between the results acquired and literature data. In short, the proposed fatigue life prediction method can shorten the product design cycle, decrease the design and product cost remarkably and improve the quality of an elastomeric pad.

\section{Keywords}

Elastomeric Pad, Fatigue Life, Finite Element Analysis (FEA), Fatigue Life Equation, Total Principal

*Corresponding author. 


\section{Strain, Chloroprene Rubber}

\section{Introduction}

Rubbers are extensively used in many applications because of their large reversible elastic deformation, excellent damping and energy absorption characteristics. Typical applications include vibration isolators for railway wagons, household electric appliances, rubber bearings for bridges, engine mounts and tires for automobiles, etc. Most of these rubber components are subjected to static and dynamic loadings in service. To prevent failures during operation is one of the critical issues in rubber component design. Therefore, fatigue analysis and strength evaluation are very important in design procedure to assure the safety and reliability of mechanical rubber components.

R. S. Rivlin [1] et al. states that fatigue strength evaluation of rubber components has relied mainly on a real road test, road simulation test, or bench fatigue test etc. Although these methods have advantages in accurate fatigue life estimation, they cannot be used before the prototype is made and the fatigue test should be always conducted whenever material or geometry changes are made. Quin $\mathrm{Li}$ [2] et al. explains the fatigue life estimation using a fatigue life curve and a fatigue damage parameter that can be determined from specimen tests and component analysis is needed for the fatigue design of the rubber components. W. V. Mars [3] et al. mentioned that maximum total principal strain and maximum strain energy density parameters have been widely used for fatigue crack nucleation prediction, and finite element method has been employed for large deformation analysis of the rubber components.W. D. Kim et al. [4] states that estimating the fatigue life of an engine mount made of natural rubber; the maximum Green-Lagrange strain and the maximum strain energy density were proper damage parameters, taking the mean load effects into account. Nonlinear finite element analysis of the 3D dumbbell specimen and engine mount were performed using Ogden hyperelastic material model determined from the tensile, shear and biaxial tension tests of the natural rubber, and resulted in relationships between load and maximum Green-Lagrange strain for both the dumbbell specimen and engine mount. H. L. Oh [5] et al. derived the model for fatigue life of a rubber bushing by using an energy balance concept (energy available versus energy required to extend a tear). This model agreed well with test results. A design procedure was developed from the model which gives the optimum insert geometry for maximum bushing life. W. V. Mars and A. Fatemi [6] observes that rubber components subjected to fluctuating loads often fail due to the nucleation and growth of defects or cracks. The prevention of such failures depends upon an understanding of the mechanics underlying the failure process. R. K. Luo [7] et al. performs FE analysis is to obtain an improved fatigue life of the spring and it is shown that a quasi-static simulation for rubber springs using nonlinear software can provide good indication for product design and failure analysis. Chang Su Woo [8] et al. refers Green-Lagrange strain at the critical location determined from the finite element method for evaluating the fatigue damage parameter of rubber mount. Fatigue life prediction equation can be effectively represented by a single function using the Green-Lagrange strain. Allen N. Gent [9] explained different approaches for predicting fatigue life of rubber like materials.

In this paper, the fatigue lifetime prediction methodology of rubber components was developed by incorporating the finite element analysis with material characterization of the rubber material and fatigue damage parameter determined from fatigue tests. The methodology was applied to the fatigue life estimation of an elastomeric pad used for railway wagons in order to assess the durability of the rubber components at the design stage.

Load versus maximum principal strain relationship of an elastomeric pad was obtained from the nonlinear finite element analysis using a hyperelastic three parameter Mooney-Rivlin model determined from material tests. Fatigue tests using dumbbell specimens with various strains were performed and a fatigue life curve represented by strain values and fatigue life in number of cycles was obtained. A fatigue life prediction equation was developed from the aforementioned fatigue life curve. Fatigue life of an elastomeric pad at different compressive loads was predicted from the fatigue damage evaluation at the critical location of the elastomeric pad and the fatigue life prediction equation.

An elastomeric pad used in railway wagons is considered in this study. Figure 1 shows a three-dimensional diagram of this elastomeric pad. An elastomeric pad was manufactured by the method of vulcanizing chloro- 


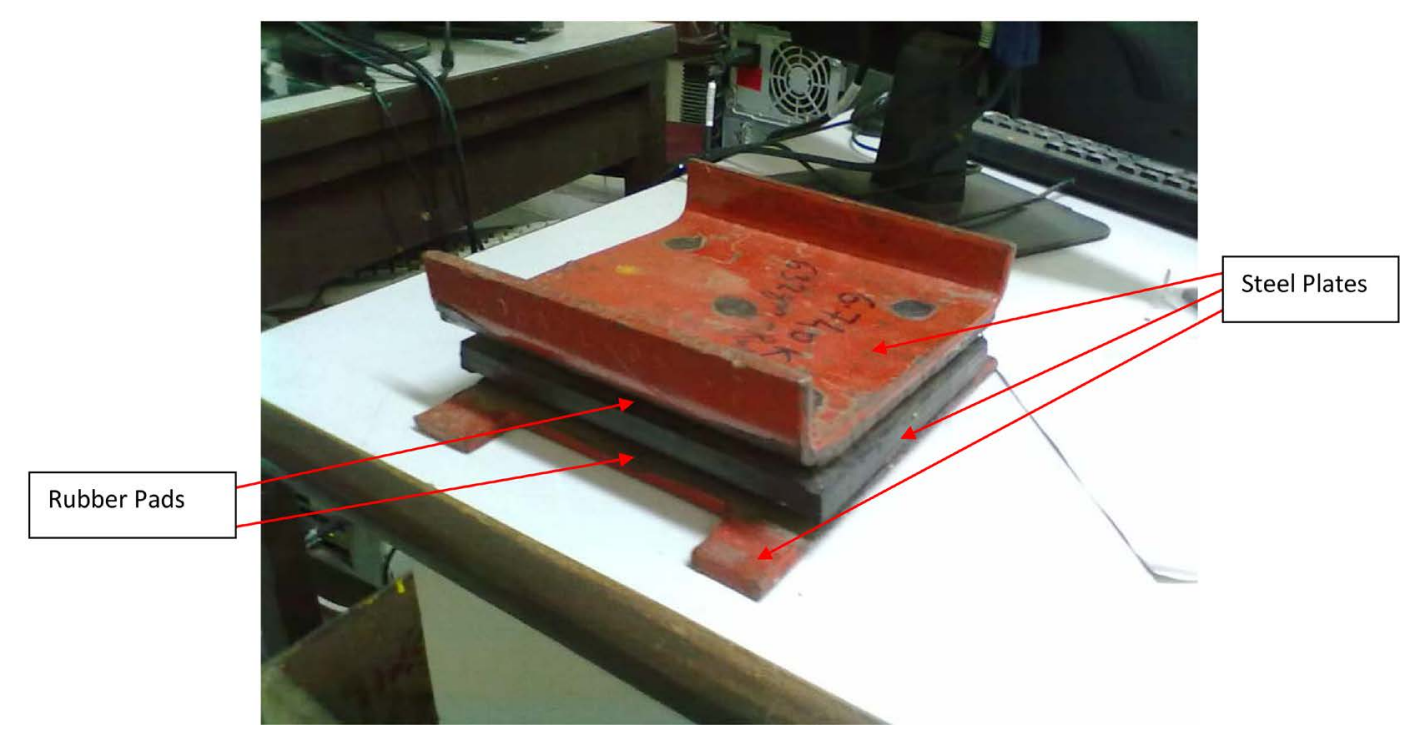

Figure 1. The three-dimensional diagram of an elastomeric pad.

prene rubber with a metal framework.

\section{Material Characterization}

\subsection{The Hyperelastic Constitutive Model of the Chloroprene Rubber Material}

The rubber material of an elastomeric pad was vulcanized chloroprene rubber, which has the hardness of the Shore A hardness degree 66. The chloroprene rubber can be considered as a hyperelastic material, showing highly nonlinear elastic isotropic behaviour with incompressibility. A relationship between stress and strain in the hyperelastic material, generally characterized by strain energy potentials, is essential for the FEA of rubber components. In order to define the hyperelastic material behaviour, i.e. the constitutive relation, experimental test data are required to determine material parameters in the strain energy potential.

The Mooney-Rivlin function was selected to specify the constitutive model of the chloroprene rubber material in this study. The strain energy potential of the Mooney-Rivlin [1] model can be expressed as:

$$
W=\sum_{i+j+k=1}^{\infty} C_{i j k}\left(I_{1}-3\right)^{i}\left(I_{2}-3\right)^{j}\left(I_{3}-3\right)^{k}
$$

where $C_{i j k}$ are set of material constants determined by the material test and $I_{1}, I_{2}$ and $I_{3}$ are first order, second order and third order strain invariants respectively and are given by:

$$
\begin{gathered}
I_{1}=\lambda_{1}^{2}+\lambda_{2}^{2}+\lambda_{3}^{2} \\
I_{2}=\left(\lambda_{1} \lambda_{2}\right)^{2}+\left(\lambda_{2} \lambda_{3}\right)^{2}+\left(\lambda_{3} \lambda_{1}\right)^{2} \\
I_{3}=\left(\lambda_{1} \lambda_{2} \lambda_{3}\right)^{2}
\end{gathered}
$$

In the uniaxial stress state, the principal stretch ratios $\lambda_{1}, \lambda_{2}$, and $\lambda_{3}$ are expressed as

$$
\lambda_{1}=\lambda_{u}, \quad \lambda_{2}=\lambda_{3}=1 / \sqrt{\lambda_{1}}
$$

where $\lambda_{u}$ is the principal stretch ratio in the loading direction, $\lambda_{2}$ and $\lambda_{3}$ are the principal stretch ratios on the planes perpendicular to the loading direction.

In this study, for more stability, the three parameter Mooney-Rivlin model expressed by Equation (6) was selected to specify the constitutive model of the chloroprene rubber.

$$
W=C_{10}\left(I_{1}-3\right)+C_{01}\left(I_{2}-3\right)+C_{11}\left(I_{1}-3\right)\left(I_{2}-3\right)
$$

where $C_{10}, C_{01}$ and $C_{11}$ are the material constants which were determined from uniaxial tensile test of the 
chloroprene rubber material. By data fit using the data acquired in uniaxial tensile tests as shown in Figure 2; we determined that $C_{10}=0.1414791, C_{01}=-0.1163389$, and $C_{11}=0.01248255$.

\subsection{The Fatigue Properties of the Chloroprene Rubber Material}

There are two methods to character the fatigue properties of the material, one is the fatigue life equation and curve of stress amplitude vs. fatigue life ( $S-N$ equation and curve), the other is the fatigue life equation and curve of strain amplitude vs. fatigue life ( $\varepsilon-N$ equation and curve). As a hyperelastic material, the chloroprene rubber's curve of strain vs. stress shows highly nonlinear characters. So the $\varepsilon-N$ equation and curve were selected to character the fatigue properties of the chloroprene rubber material.

In order to evaluate the fatigue properties of the chloroprene rubber, fatigue tests on dumbbell specimens as per ASTM D412 standards [10] were performed. Fatigue tests were conducted in an ambient temperature of $25^{\circ} \mathrm{C}$ by using endurance testing machine at IRMRA. A dumbbell specimen with sectional dimension shown in Figure 3 was used for the fatigue tests. The dumbbell specimen was subjected to cyclic loading with constant amplitude, sinusoidal cyclic displacements with a mean displacement of zero, and frequency of $5 \mathrm{~Hz}$. With increasing cycles in the initial phase, the maximum load decreased little by little. When the crack grew over the critical size, the maximum load decreased suddenly and the final failure reached. In order to detect the appearance of fatigue cracks, the specimen surface was visually observed during the test at regular time intervals. The fatigue failure was defined as the number of cycles necessary to obtain a crack of $1 \mathrm{~mm}$ size in the dumbbell specimen. The fatigue test results of the dumbbell specimens are shown in Table 1.

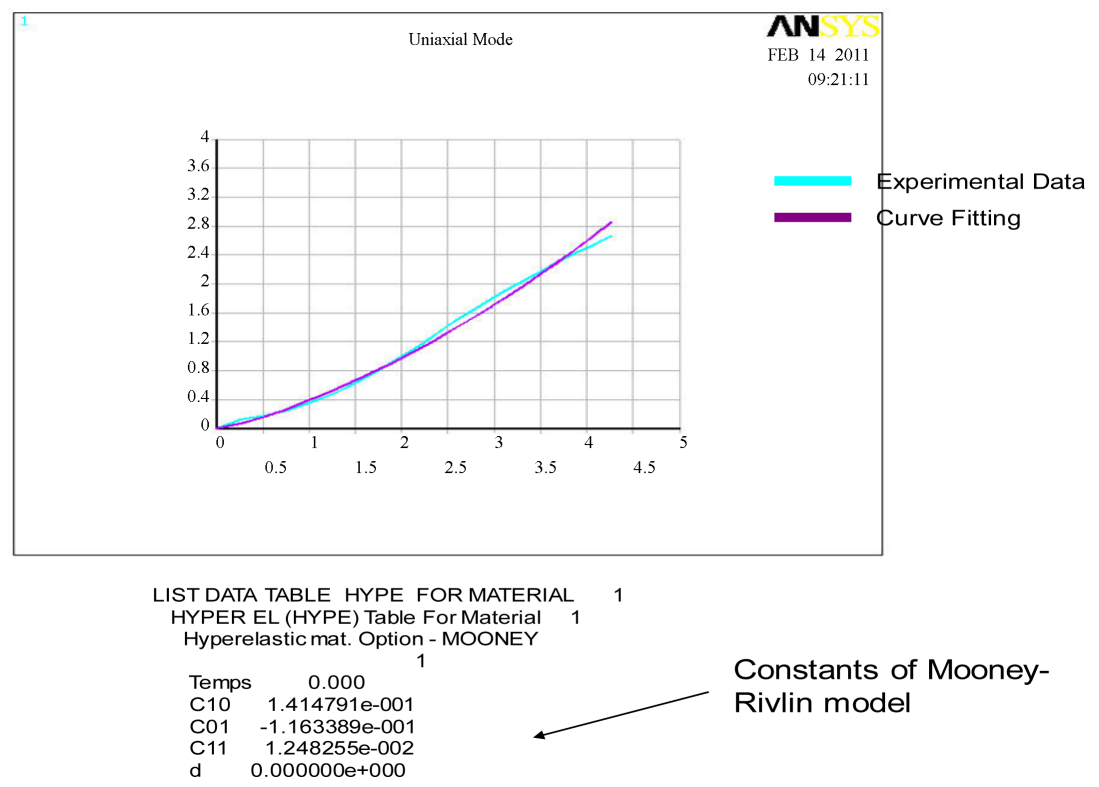

Figure 2. The uniaxial tensile stress vs. strain curves of the rubber material.

Table 1. The dumbbell specimen of the chloroprene rubber (all the dimensions are in $\mathrm{mm}$ ).

\begin{tabular}{ccc}
\hline Sr. No. & Strain Value (\%) & Fatigue Life in No. of Cycles $(N)$ \\
\hline 1 & 25 & $7,19,987$ \\
2 & 50 & $3,36,003$ \\
3 & 65 & $1,68,078$ \\
4 & 75 & 88,012 \\
5 & 85 & 39,992 \\
6 & 100 & 32,053 \\
\hline
\end{tabular}


The $\varepsilon-N$ curve shown in Figure 4 in the double logarithmic co-ordinates can be treated as a line which is shown in Figure 5 . So the fatigue life equation of the chloroprene rubber can be expressed as:

$$
\varepsilon^{m} N=C
$$

where the $m$ and $C$ are the moduli determined by test of material properties. The values of $m$ and $C$ de termined by fatigue test results using the least square method are 6.277 and 27,805 respectively.

So the fatigue life equation of the chloroprene rubber can be expressed as:

$$
\varepsilon^{6.277} N=27805
$$

Equation (8) can be transformed as:

$$
m \log \varepsilon+\log N=\log C
$$

So the fatigue life equation of the chloroprene rubber in the logarithmic co-ordinates can be expressed as:

$$
\log \varepsilon=0.708-0.157 \log N
$$

Equation (10) was used to predict the fatigue life of an elastomeric pad in number of cycles. In this equation the maximum values of the strain was substituted from FEA analysis to get the fatigue life in number of cycles at different compressive loads.

\section{FEA of an Elastomeric Pad}

The model of an elastomeric pad shown in Figure 6 was analysed by ANSYS software. An elastomeric pad consists of three mild steel plates separated by two chloroprene rubber pads. These different materials were considered perfectly bonded to one another. The four node plane 182 element was selected for the model. The three parameter hyperelastic material nonlinear Mooney-Rivlin model was used for the analysis.

The deformed shape and strain contour for 10 tonne compressive load is shown in Figure 7. The regions

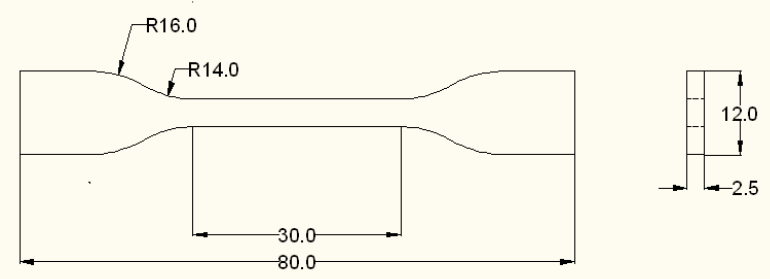

Figure 3. The dumbbell specimen of the chloroprene rubber (all the dimensions are in $\mathrm{mm}$ ).

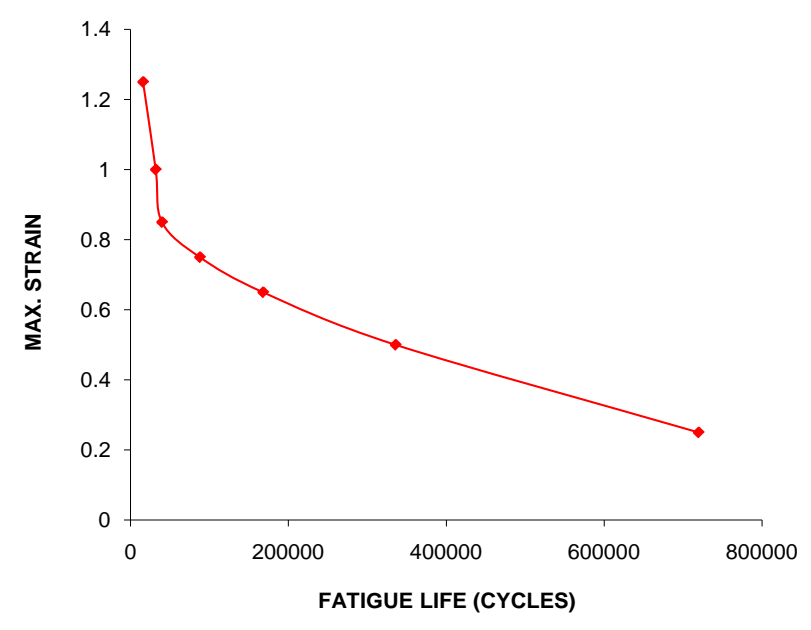

Figure 4. Fatigue life test results and the $\varepsilon-N$ curve of the chloroprene rubber material. 


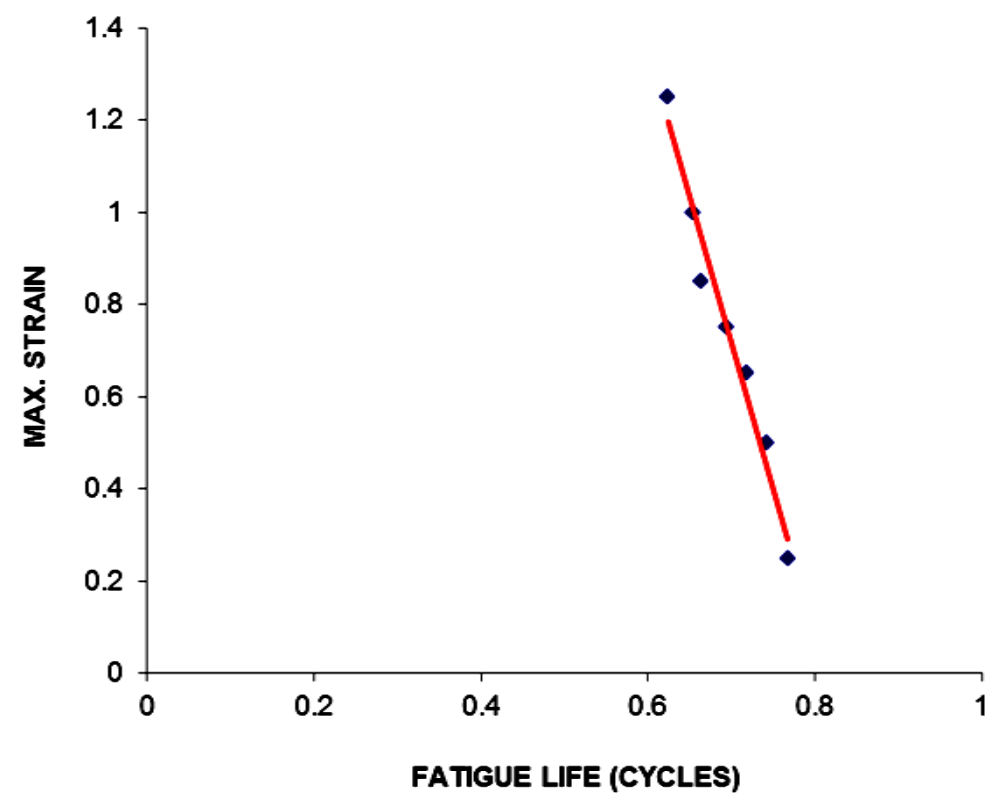

Figure 5. The $\varepsilon-N$ curve of the chloroprene rubber in the double logarithmic co-ordinates.

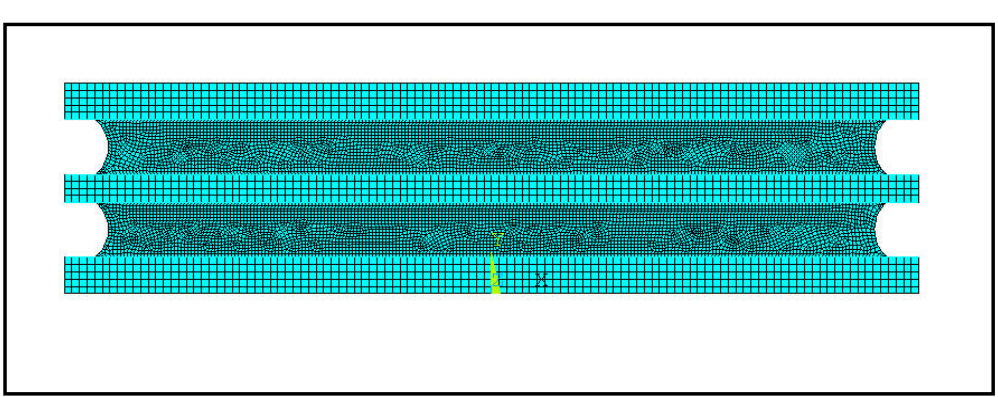

Figure 6. Finite element model of an elastomeric pad.

showing the maximum total principal strains are the critical regions where the cracks prone to arise.

Analysed and recorded the maximum total principal strains at different compressive loads by the above FEA method. Figure 8 shows the maximum total principal strains at different compressive loads.

\section{The Fatigue Life Prediction of an Elastomeric Pad}

It is considered that an elastomeric pad cracks when the critical region suffered sufficient fatigue damage i.e. when a crack of $1 \mathrm{~mm}$ size is observed. The maximum total principal strain at the critical region determined from the FEA was used for evaluating the fatigue damage parameter of the chloroprene rubber. The fatigue lives of an elastomeric pad at different compressive loads were derived by substituting the maximum total principal strains into the fatigue life equation of the chloroprene rubber material.

The fatigue life of an elastomeric pad was predicted using the above method incorporating test of material properties and FEA. Table 2 and Figure 9 show the predicted fatigue life of an elastomeric pad at different compressive loads.

\section{Conclusion}

The fatigue life of an elastomeric pad was predicted through a combination of test of the material properties and FEA in the early design procedure to assure the safety and reliability of an elastomeric pad. The chloroprene rubber material was a newly developed rubber material for an elastomeric pad to meet the specified technical requirements; therefore it is necessary to predict the fatigue life of the pad before the prototype or actual com- 


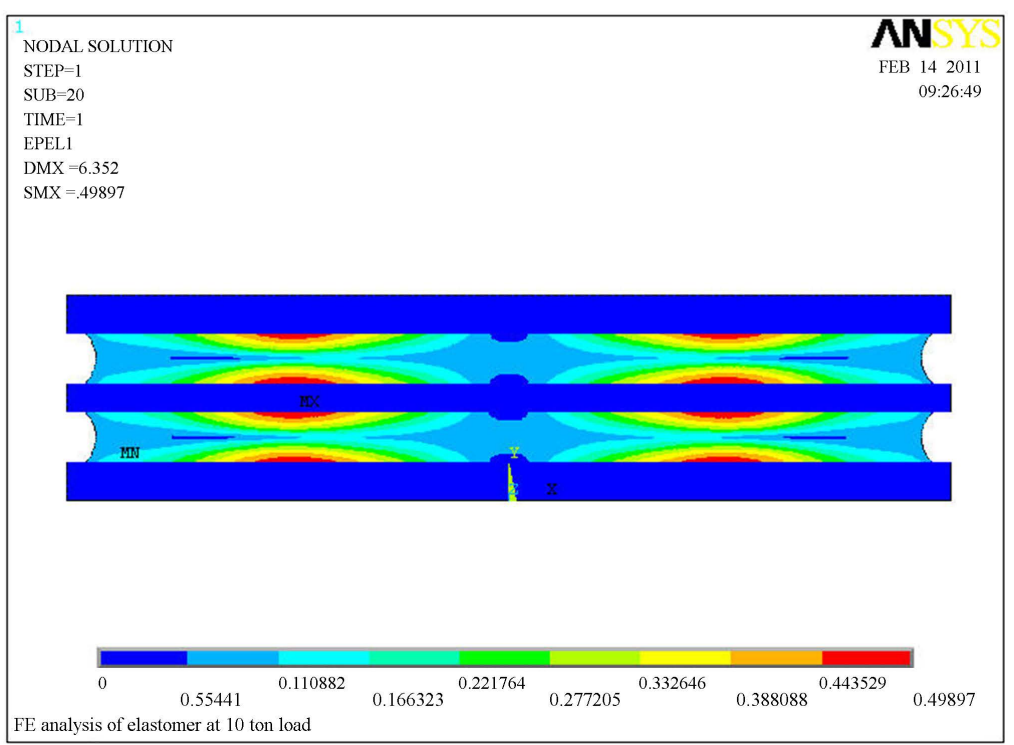

Figure 7. The deformed shape and strain contour for 10 tonne compressive load.

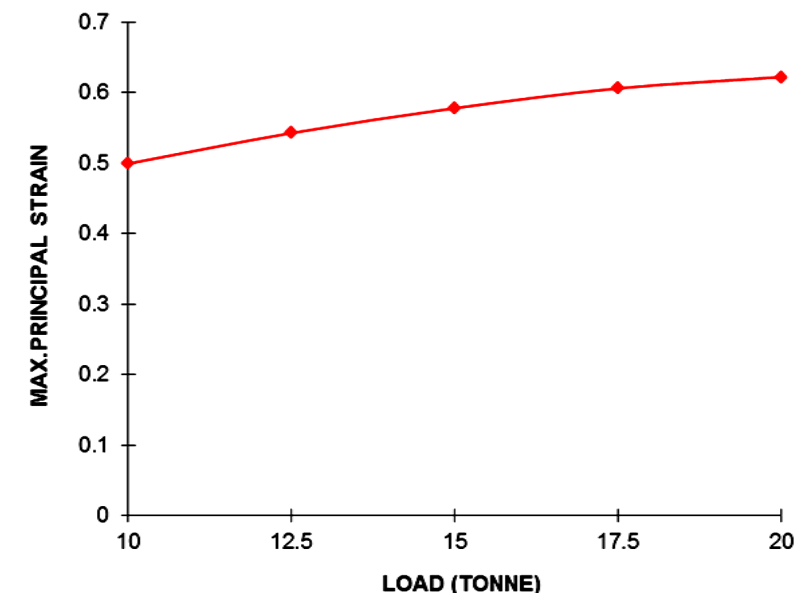

Figure 8. The maximum total principal strain at different loads.

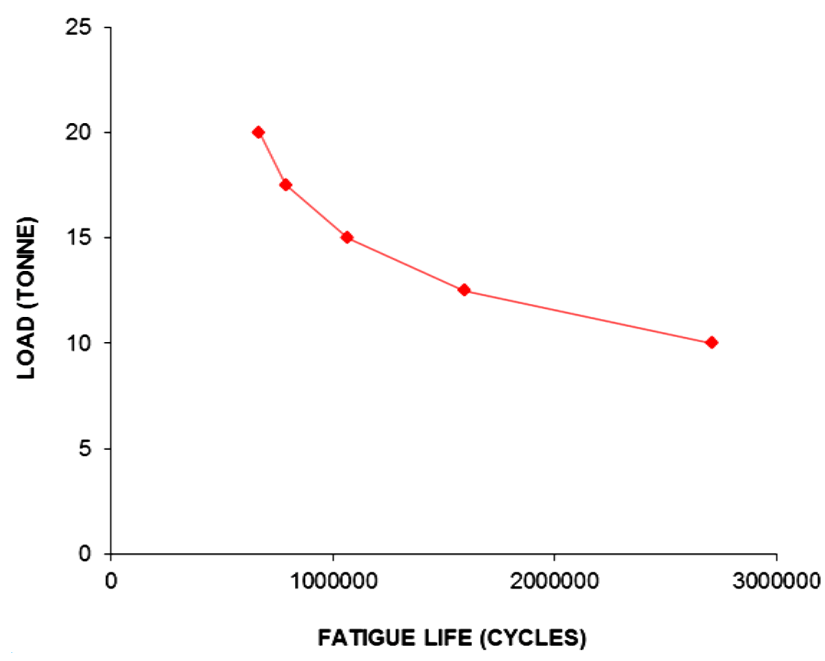

Figure 9. Predicted fatigue life in cycles at different loads. 
Table 2. The predicted fatigue life of an Elastomeric pad at different loads.

\begin{tabular}{|c|c|c|c|c|c|c|}
\hline \multirow{2}{*}{ Sr. No. } & \multirow{2}{*}{ Parameters } & \multicolumn{5}{|c|}{ Load in Tone } \\
\hline & & 10 & 12.5 & 15 & 17.5 & 20 \\
\hline 1 & Max. $\mathrm{I}^{\text {st }}$ principal elastic strain $(\varepsilon)$ & 0.49897 & 0.542378 & 0.577614 & 0.605677 & 0.621768 \\
\hline 2 & Fatigue life in cycles $(N)$ & $2,707,981$ & $1,591,834$ & $1,066,069$ & 788,050 & 666,843 \\
\hline
\end{tabular}

ponent is made. The strain analysis of an elastomeric pad is carried out by using FEA which outlines the critical regions having maximum principal strain in which the cracks prone to arise. Therefore, the first evidence of fatigue failure will be observed in these critical regions. It is observed that as the compressive load on an elastomeric pad increases; the maximum principal strain is also increases and the fatigue life in number of cycle decreases. The predicted fatigue life of an elastomeric pad at maximum 20 tonne load is greater than 5 lac cycles i.e. 666,843 cycles. This satisfies the fatigue requirement of the RDSO which states that after fatigue testing of the pad for 5 lac cycles there should not be any sign of crack or bond failure.

\section{Acknowledgements}

The authors are thankful to Indian Rubber Manufacturer's Research Association, Thane (W) and Management of Pune District Education Association and Dr. K. R. Harne, Principal, College of Engineering, Manjari (Bk.), Pune, for granting the permission to do the research work on the aforementioned topic.

\section{References}

[1] Rivlin, R.S. and Sawyers, K.N. (1976) Strain-Energy Function for Elastomers. Transactions of Society of Rheology, 20, 545-557. http://dx.doi.org/10.1122/1.549436

[2] Li, Q., Zhao, J.-C. and Zhao, B. (2009) Fatigue Life Prediction of a Rubber Mount Based on Test of Material Properties and Finite Element Analysis. Engineering Failure Analysis, 16, 2304-2310. http://dx.doi.org/10.1016/j.engfailanal.2009.03.008

[3] Mars, W.V. and Fatemi, A. (2002) Factors That Affect the Fatigue Life of the Rubber: A Literature Survey. Rubber Chemistry and Technology, 77, 391-412.

[4] Kim, W.D., Lee, H.J., Kim, J.Y. and Koh, S.K. (2004) Fatigue Life Estimation of an Engine Rubber Mount. International Journal of Fatigue, 26, 553-560. http://dx.doi.org/10.1016/j.ijfatigue.2003.08.025

[5] Oh, H.L. (1980) A Fatigue-Life Model of a Rubber Bushing. Rubber Chemistry and Technology, 53, 1226-1238. http://dx.doi.org/10.5254/1.3535090

[6] Mars, W.V. and Fatemi, A. (2002) A Literature Survey on Fatigue Analysis Approaches for Rubber. International Journal of Fatigue, 24, 949-961. http://dx.doi.org/10.1016/S0142-1123(02)00008-7

[7] Luo, R.K. and Wu, W.X. (2006) Fatigue Failure Analysis of Anti-Vibration Rubber Spring. Engineering Failure Analysis, 13, 110-116. http://dx.doi.org/10.1016/j.engfailanal.2004.10.012

[8] Woo, C.S. and Kim, W.D. (2006) Heat-Aging Effects on the Material Properties and Fatigue Life Prediction of Vulcanized Natural Rubber. Journal of Soft Materials, 2, 7-12. http://dx.doi.org/10.2324/ejsm.2.7

[9] Gent, A.N. (2007) Engineering with Rubber. Hanser Gardner Publications, Ohio.

[10] A Handbook of ASTM Standards (1984) Rubber Products, Industrial Specifications and Related Test Methods. 9.02, 145-146. 